\title{
A VIOLÊNCIA URBANA NA IMPRENSA: ALGUMAS CONSIDERAÇÕES'
}

\author{
Adriana de Fátima Ferreira \\ Mestranda em Ciências Sociais \\ na Universidade Estadual de Londrina
}

\section{Resumo}

A violència urbana tem sido uma questão bastante discutida pelos meios de comunicação. o que pode ser constatado a partir da verificação da quantidade de notícias que aparecem sobre os mais diferentes atos considerados "violentos". Por isso, este artigo procura realizar uma reflexão acerca da violência urbana e da forma como esta tem sido retratada pela imprensa escrita, tendo como ponto de partida a análise das notícias sobre práticas violentas ocorridas no meio urbano e veiculadas pelo jornal Folha de São Paulo durante o ano de 1996.

Palavras-chave: violência urbana; imprensa; notícias.

proposta deste trabalho é iniciar uma discussão que problematize as questões que envolvem a violência urbana e como ela vem sendo tratada pelo jornal.

Esta preocupação tem como justificativa o fato de que, nos últimos anos, os meios de comunicação em geral vêm demostrando grande interesse na divulgação de notícias de práticas consideradas violentas, ou seja, latrocínios, homicídios, roubos, estupros, chacinas, agressões físicas, etc. Há muitos programas e cadernos e são muitos os comentaristas que tratam especificamente dessas notícias.

Quanto ao consumo desses "produtos culturais", é impossível negar a influência que eles exercem em diversas camadas da população

\footnotetext{
' Este trabalho é uma adaptação da monografia intitulada " $O$ (re)trato da violência arrave's do tevto jornalístico" apresentada como trabalho de conclusão do curso de Especialização em Sociologia e Sociologia da Educação da UEL, em 1997, sob orientação da Prof" Dra Maria José de Rezende.
} 
brasileira. A preocupação com uma violência difusa tem se tornado cada vez mais presente.

Esta problemática é bastante relevante para a Sociologia, uma vez que compreender os processos que envolvem a articulação entre violência e imprensa implica considerar a complexidade das relações que constituem a sociedade brasileira.

Para analisar a violência urbana brasileira é necessário examinar uma série de peculiaridades. É fundamental entender a violência no Brasil como um processo complexo (SUSSEKIND,1987) que envolve algumas variáveis (VELHO,1987) denominadas objetivas (econômicas e políticas) e subjetivas (culturais e sociais).

Como variáveis ou elementos "objetivos", por um lado, consideram-se as condições de sobrevivência efetivamente colocadas pelos agentes econômicos, que determinam e influenciam concretamente a existência das pessoas na sociedade. Fatores estruturais são, portanto, fundamentais para o entendimento da violência urbana, visto medida que a extrema concentração de renda verificada em nosso país, aumenta significativamente o número de pessoas empobrecidas e que estão à margem de qualquer decisão política.

Por outro lado, existem os elementos "subjetivos", que são os aspectos culturais da sociedade, notadamente no que diz respeito à existência de determinados valores que permeiam as decisões, escolhas e opiniões da população.

É a partir desta perspectiva que trabalha José de Souza Martins (1995). Para ele, alguns tipos específicos de violência urbana sugerem haver um sistema de valores subjacentes às condutas violentas do comportamento coletivo, arraigadas à própria cultura brasileira. Assim, os indivíduos, ao agirem de forma considerada violenta, estariam apenas reproduzindo as próprias condições às quais estão sujeitos em sua vida cotidiana, ou seja, as que já fazem parte de sua cultura e, por esse motivo, se encontram internalizadas em suas mentes.

Dessa forma, constatando que as imagens veiculadas pelos meios de comunicação são fundamentais para a formação da opinião pública dos interlocutores a respeito dos assuntos que são tratados (BENEVIDES, 1983), a abordagem central deste artigo refere-se à violência urbana e à forma como ela é tratada pela imprensa, tendo como fonte 
de dados o caderno Cotidiano do Jornal Folha de São Paulo, no período de janeiro a dezembro de 1996.

\section{A imprensa na sociedade capitalista}

Além de formadora da opinião pública, a imprensa ocupa importante lugar na organização e seleção das informações e na produção das notícias. Assim como as demais empresas no interior do modo de produção capitalista, a imprensa trabalha com objetivo de, utilizando-se de uma matéria-prima - a informação -, criar um produto para ser comercializado na sociedade.

Jürgen Habermas (1984, p.141) demonstra como se processou o desenvolvimento da empresa jornalística, relacionando as transformações decorrentes dessa instituição com o contexto político-social no qual ela estaria inserida. Segundo o autor, esse processo iniciou-se no momento em que a principal característica do jornalismo se alterou: (...) "a imprensa informativa passa a tender para a imprensa de opinião". Esta mudança teria acarretado significativas transformações na organização das funções internas do jornal, principalmente no que diz respeito ao consequiente interesse e atenção que passam a ser concedidos à redação do jornal, assim como ao redator, que, a partir de então, passa a ter seu trabalho e profissão mais valorizados. Ao mesmo tempo, o editor; que antes tinha seu trabalho norteado pelo objetivo de "informar" a população, passa a comercializar "opinião pública".

Uma grande distância afasta esta fase do jornalismo artesanal quando o editor selecionava as informações com o interesse único de possibilitar ampla divulgação das mesmas -, ou ainda do jornalismo literário - que privilegiava o aspecto redacional com vistas a se constituir um elemento de expressão da opinião pública. A imprensa, como atividade capitalista, passa a ter como norteadores interesses que nem sempre correspondem à sua natureza de órgão divulgador de informações. Interesses privados, ou ainda, de grupos, muitas vezes alheios, são destacados, em detrimento da atividade jornalística em si.

Todos esses aspectos estruturais estão diretamente relacionados ao movimento de concentração e centralização do capitalismo $\mathrm{m}$ 
âmbito mundial, à medida que se formam os "primeiros conglomerados jornalísticos" na Inglaterra, nos Estados Unidos e na Alemanha. Paralelamente, cresce também a utilização e a influência das inovações tecnológicas de fins do século XIX junto à imprensa, e sobretudo, no que se refere à constituição dos meios de comunicação de massa.

Antônio Gramsci (1979) apresenta uma definição de jornalismo segundo a qual este seria um processo dinâmico, que acompanha a sociedade capitalista, em contínuo desenvolvimento e ampliação de sua influência, de modo que as necessidades nunca seriam satisfeitas, apenas, recriadas. Nesse sentido, o autor coloca a imprensa como reprodutora das relações sociais de produção, considerando o leitor elemento fundamental quando da organização da empresa jornalística, concebendo-o com base em duas perspectivas distintas e complementares: como "elemento ideológico" (isto é, ele é maleável, podendo ser transformado), e como "elemento econômico" (o que significa dizer que ele possui a capacidade de adquirir as publicações que the são oferecidas). Assim, a empresa jornalística deve orientar-se com base nesses elementos, ou seja, realizar sua programação considerando as especificidades dos leitores (camada social, linguagem, interpretação da realidade, contexto social, etc.), de forma que eles sejam estimulados a adquirir as publicações, possibilitando a realização do valor de troca dessas mercadorias, que são oferecidas no mercado.

Semelhante posicionamento possui Ciro Marcondes Filho (1984) ao caracterizar a função do jornalismo na sociedade capitalista, relacionando-o à estrutura de poder que se configura na sociedade. De acordo com esse autor, o jornalismo se constituiria um mecanismo utilizado para recriar, reelaborar uma determinada realidade, de modo que esta esteja cada vez mais de acordo com as diretrizes da classe que está no comando. Dessa forma, a criação do jornal não corresponderia ao real; ao contrário, o jornalismo moldaria a realidade, de modo a construir uma natureza diferente do concreto, promovendo nos indivíduos uma sensação de harmonia, de satisfação e, consequentemente, de imobilidade, inviabilizando qualquer reação do indivíduo diante do contexto que o cerca.

Theodor W. Adorno (1986, p.92), se refere ao lugar do consumidor quanto à produção dos bens do que denomina indústria cultural. 
Segundo ele, a sociedade capitalista moderna organizou um sistema de produção cultural estruturado nos interesses capitalistas de consumo, utilizando-se da tecnologia e da concentração econômica e administrativa características do moderno capitalismo, com o objetivo de produzir uma integração, uma homogeneização entre os indivíduos consumidores, de modo que o consumo seja, também, cada vez mais homogêneo, instantâneo:

"A indústria cultural é a integração deliberada, a partir do alto, de seus consumidores. Ela força a união dos domínios, separados há milênios, da arte superior e da arte inferior. Com prejuízo para ambos. A arte superior se vê frustrada de sua seriedade pela especulação sobre o efeito; a arte inferior perde, através de sua domesticação civilizadora, o elemento de natureza resistente e rude, que lhe era inerente enquanto o controle social não era total.(...) \{Nesse processo\}, as massas não são, então, o fator primeiro, mas um elemento secundário, um elemento de cálculo; acessório da maquinaria. O consumidor não é rei, como a indústria cultural gostaria de fazer crer, ele não é o sujeito dessa indústria, mas seu objeto. (...) A indústria cultural abusa da consideração com relação às massas para reiterar, firmar e reforçar a mentalidade destas, que ela toma como dada a priori e imutável. É excluído tudo pelo que essa atitude poderia ser transformada. As massas não são a medida mas a ideologia da indústria cultural, ainda que esta última não possa existir sem a elas se adaptar. As mercadorias culturais da indústria se orientam, (...) segundo o princípio de sua comercialização e não segundo seu próprio conteúdo e sua figuração adequada." (ADORNO,1986, p.92-93)

O domínio da indústria cultural é significativo, mormente no que se refere ao processo contínuo de reforçar a mentalidade, os princípios e valores que a mantêm numa condição de apatia e imobilismo, permeada pela ideologia cotidianamente transmitida pelas imagens veiculadas pelos meios de comunicação social. Mais do que isso, a indústria cultural procura disseminar entre a sociedade uma idéia de ordem, ao mesmo tempo em que impede o desenvolvimento crítico, a autonomia dos indivíduos, privando-os de realizar conscientemente suas escolhas e julgamentos. (ADORNO, 1986, p. 99). 


\section{A produção da notícia}

O jornal não se preocupa com as origens, com a contextualização da informação; seu interesse repousa no que permite rápido consumo, nas informações que podem ser "vendidas" à população. Essa tendência pode ser demonstrada, dentre outras maneiras, $\mathrm{p}$ meio da análise das próprias manchetes do jornal, que procuram atrair instantaneamente a atenção do leitor: Medo cria 'toque de recolher' em SP(LOZANO, 1996a): Periferia tem extermínio masculino (TREVISAN, 1996); Rio gratifica policial que mata mais (TORRES, 1996); A epidemia da violência (TOLEDO, 1996); Dicas de segurança em SP (DICAS...1996). Para se produzir a notícia, as informações selecionadas devem ser descoladas do contexto maior que as geraram. Em consequiência disto, o leitor não estará em condições de avaliar o que leu ou então elaborar uma conclusão a respeito do que leu.

A redação da notícia, por sua vez, procura vincular-se à publicidade do jornal, transmitindo ao leitor uma suposta neutralidade e a separação entre notícias e anúncios, que, na verdade, somente oculta uma harmonia produzida entre ambos os elementos para favorecer o aumento de seu consumo. Confundem-se, dessa forma, as esferas e encobre-se a realidade: informação e publicidade interpenetram-se.

Sendo a informação a matéria-prima de uma mercadoria como as demais na sociedade capitalista, a notícia deve ser atraente, deve ter sua aparência alterada. Isso significa, em outras palavras, criar uma "aparência" de valor de uso, pois, sendo a notícia uma mercadoria rapidamente perecível, é fundamental renová-la, alterá-la constantemente, de modo a "atender" determinadas necessidades e expectativas.

Quanto ao caráter fetichizado da mercadoria notícia, Marcondes Filho (1986b) destaca a alienação do trabalho, decorrente do processo de fragmentação (da produção, do conhecimento, dos sentimentos, etc.) predominante na sociedade capitalista, como uma "estratégia mercadológica" importante à empresa jornalística. De acordo com essa estratégia, os indivíduos estão de tal forma inseridos no processo capitalista - fragmentado - de produção que não conseguem se reconhecer no produto de seu trabalho.

Em se tratando de fetichização, esses indivíduos estão duplamente sujeitos à fragmentação. Por um lado, mesmo longe da atividade 
produtiva propriamente dita, em seus momentos de lazer, apresentam uma mentalidade também dividida. Por outro, os produtos que thes são transmitidos pela indústria cultural (ADORNO, 1986), entre os quais o jornal, são também fragmentados, descontextualizados, autônomos, sem vinculação com a realidade mais ampla, impedindo que o leitor-consumidor construa uma análise mais ampla da sociedade na qual está inserido.

Assim, torna-se difícil que se compreendam as reais causas, consequências e implicações das dificuldades e dos. "problemas sociais" existentes, à medida que se perdem de vista os elementos necessários a uma ótica macrossocial, impossibilitada por uma visão, segundo a qual, a sociedade seria formada por indivíduos e não por classes sociais. Este processo, portanto, imobiliza os indivíduos, à medida que eles não conseguem identificar exatamente os agentes responsáveis pelos problemas, com os quais, ou contra os quais, devam se mobilizar.

\section{A violência no Brasil}

No que se refere à constituição da sociedade brasileira, os dados históricos relativos ao predomínio da violência não podem ser ignorados: o Brasil é um país que desde sua colonização vem sofrendo um processo marcante de violência social (COSTA, 1996). Esta violência, no entanto, não teve e não tem uma única forma de manifestação - “(...) é que não há violência, há violências" (SUSSEKIND, 1987, p.10) -, da mesma forma que os autores e vítimas das práticas violentas são igualmente diversos, não havendo um único segmento ao qual possa ser atribuída a caracterização de violento ou violentado. Na verdade, o que se pode afirmar $\mathrm{cm}$ base nisso é que a violência não se limita à criminalidade, antes ela constitui-se um processo mais complexo, incluindo as esferas econômica, política, doméstica, educacional, urbana, rural, etc.

"Se violência é a criminalidade violenta, então violência não é a poluição que assola os rios, nossas plantações, nossos centros urbanos, nossa alimentação, nossos tímpanos, nossa paisagem. Violência também não é a incerteza do mercado financeiro, flagelado pelas inúmeras fraudes e falcatruas. Não é a educação 
esdrúxula e elitista que pretende domesticar os brasileiros das mais diversas localidades sob um mesmo padrão, absolutamente alienado de seu cotidiano. Não é o sistema de assistência médica, ou as dezenas de milhões de menores oficialmente assumidos como 'carentes' (...)” (SUSSEKIND, 1987, p. 10)

Na discussão das causas da violência, a idéia mais recorrente entre grande parte da população está relacionada à pobreza: muitas vezes, considera-se a violência como consequiência imediata das condições miseráveis de sobrevivência da população, numa clara relação mecanicista. Assim sendo, é preciso, primeiramente, segundo Edmundo Campos (1980), desmontar a tese de associação positiva entre nível econômico baixo e criminalidade. Apesar de não corresponder à verdade, esta tese foi apresentada inúmeras vezes e, de certa forma, defendida por trabalhos de pesquisadores que se limitaram a analisar as estatísticas sobre criminalidade produzidas pelas instituições responsáveis pelo policiamento - e também pela repressão - e segurança da população, concedendo a estas estatísticas um caráter de verossimilhança que nem sempre corresponde à realidade.

Outros trabalhos contribuem para uma análise mais apurada da "associação" entre criminalidade e pobreza, como o de Gilberto Velho (1987). Segundo ele, deve ser enfatizada a questão das posições ocupadas pelos grupos na hierarquia social. Na verdade, sendo o Brasil um país que possui distribuição de renda extremamente desigual, onde os canais de participação política são restritos a alguns poucos segmentos, a maior parte da população encontra-se completamente à margem das decisões, determinando portanto, diferentes posições no jogo político que, por sua vez, determinarão diferentes formas de participação social.

Outro dado fundamental para se pensar sobre as origens da violência diz respeito à própria cultura brasileira. Entre as implicações do modelo colonial aqui instalado, destaca-se a questão do longo processo de escravidão (VELHO, 1987): juntamente com outros elementos, o uso da força e da violência - práticas largamente utilizadas para legitimar uma ordem social excludente - pode ser considerado como importante fator, responsável pela constituição dos valores e das condutas morais que formam a sociedade brasileira. 
Outra importante implicação deste modelo colonial é o fato de que há muito tempo, certas camadas sociais têm sido as únicas a ocupar os espaços políticos, em detrimento da maior parte da população, excluída do cenário político, econômico e social.

Ao tratar da violência, Marilena Chauí enfatiza aspectos da cultura brasileira que, segundo ela, teriam disseminado junto à sociedade uma violência institucionalizada, porém imperceptível, porque difusa, a qual ela denomina "violência horizontal". Contrariamente à violência "vertical" - a violência visível, exercida de cima para baixo sobre a sociedade - a violência horizontal seria invisível, porque se encontra espalhada pelo interior das relações sociais.

Em virtude desse processo de institucionalização de uma violência invisível, ter-se-ia desenvolvido no Brasil uma cultura violenta, sob uma aparência de não-violência - o que Chauí denomina o mito da não-violência do brasileiro. Com base nesse mito são constituídas algumas explicações quase consensuais para o "problema da violência urbana no Brasil", estando, na maior parte das vezes, relacionadas às consequências negativas da urbanização, industrialização e migração desenfreadas, que gerariam condições favoráveis à ocorrência de atos violentos, à medida que a miséria, a marginalização, a concentração de renda se acentuariam desordenadamente. Assim, a violência é "vista como uma resposta circunstancial à situação de disfunção social causada por essa transição" (CHAUÍ, 1980, p.17). Mais do que isso, essas explicações contribuem para encobrir a violência institucionalizada, à qual toda a sociedade está submetida, permitindo, ainda, conservar o "mito da não-violência" do brasileiro, de que são originárias.

Ao definir violência, Marilena Chauí (1980) parece inverter a ordem habitual, onde são considerados violentos todos os atos que infringem normas, leis, regras aceitas pela maioria da população - ou seja, a violação. Ela, ao contrário, relaciona a violência com a dominação, com a interiorização da obediência, com o objetivo de promover a padronização dos indivíduos, a redução dos seres humanos a objetos obedientes, processo este que se espalha por todas as instituições da sociedade civil, orientado e coordenado pelo Estado, que dá forças e garante a sobrevivência do mito da não violência: 
"O mito é construído graças a um processo de exclusão social e histórica preciso, cuja finalidade é admitir a existência inegável de violência, mas fazendo-a aparecer de modo a negá-la. O primeiro mecanismo de aceitação-negação da violência consiste em tomá-la como um acontecimento esporádico ou acidental e não como constitutiva da própria sociedade brasileira (...)" (CHAÚ, 1980, p. 16)

Tomando-se isso por base, a caracterização de violência, segundo a autora, diverge significativamente das análises - jurídicas, segundo ela - que se propagam entre os diversos segmentos da sociedade civil. Em suas palavras, violência é o

"Processo pelo qual um indivíduo (humano ou não) é transformado de sujeito em coisa (...). Estamos habituados a considerar a violência pelo prisma da violação, isto é, como transgressão de regras, normas e leis aceitas por uma coletividade e das quais ela depende para continuar existindo (...) Definindo aqui a violência como processo de redução de um sujeito à condição de coisa, visamos a retirá-la do contexto que a define como transgressão de regras e de leis para pensar nestas regras e nestas leis como portadoras de violência. Em outras palavras, a violência se encontra originariamente do lado da sujeição e da dominação, da obediência e de sua interiorização, e não do lado da violação dos costumes e das leis." (CHAUÍ, 1980, p. 16)

O trabalho de Maria Victória Benevides (1983) é também bastante elucidativo. Estudando especificamente a questão da violência urbana na imprensa, num período que vai de 1979 a 1981, ela apresenta inúmeras questões bastante relevantes para a discussão que ora se realiza, como a discussão sobre causas e soluções para a criminalidade e violência no Brasil.

Basicamente, a autora identificou duas diferentes vertentes daquele que diz respeito à identificação das causas da violência. Segundo ela, existe um discurso oficial - que abrange as respostas dadas por autoridades do Executivo ou do Legislativo, bem como de autoridades civis e militares vinculadas à estrutura de Segurança e Justiça - e um discurso não oficial, alternativo - que inclui diversos segmentos da sociedade civil, como representantes de associações, juristas e profis- 
sionais do Direito como um todo, e também profissionais da área de Ciências Sociais e analistas políticos. (BENEVIDES, 1983, p.30)

A cada um destes dois discursos correspondem visões específicas quanto às causas da violência e, consequentemente, diferentes propostas para a resolução desta questão. O discurso oficial não relaciona o problema da violência urbana com o sistema econômico vigente, não questionando o modelo capitalista de produção. Ao contrário, reforça a tese de que os problemas socioeconômicos decorrentes do acelerado processo de industrialização e urbanização são os principais responsáveis pela criminalidade, juntamente com as deficiências do sistema policial vigente e com o caráter "inato" dos "infratores".

Um posicionamento distinto tem o discurso não-oficial, "alternativo", apresentando uma reflexão mais complexa, onde se relacionam as implicações relativas ao modelo capitalista de produção, bem como outras falhas estruturais do sistema Judiciário, penitenciário e policial.

\section{A violência na imprensa: análise dos textos jornalísticos}

Verifica-se uma tendência crescente - já apontada - e que deve ser considerada: o interesse demonstrado por jornais e emissoras de televisão, em manter seções e programas que, diariamente, veiculem os mais diversos tipos de atos "violentos", produzindo a idéia de uma "onda de violência".

Como já fora dito, no que diz respeito à produção da notícia, a orientação seguida pelos meios de comunicação, e especialmente pelo jornal, está vinculada às determinações colocadas pelo modo de produção capitalista de produção da notícia, passando por diferentes processos, de forma que sejam "atendidas" as necessidades do mercado.

Em relação ao aspecto de manutenção da estrutura social, Ailton Benedito de Souza explica a importância da violência para esse fim, como um importante componente que oculta o real e se preocupa em transmitir falsas imagens que deverão, por sua vez, proporcionar a manutenção da também aparente ordem. 
“(...) se estamos diante de uma sociedade dividida em classes antagônicas, baseada na exploração dos despossuídos pelos possuidores dos meios de produção, observar-se-á, no nível ideológico, todo um milenar trabalho de obscurecimento e mascaramento das opressivas relações de produção e ordenamento social, trabalho correspondente aos desejos das classes dominantes.(...) A criação e veiculação, pelos mass media, do conteúdo ideológico 'violência' no mundo atual (...) é um evidente exemplo do funcionamento dos aparelhos da estrutura ideológica de uma sociedade dividida em classes antagônicas, na sua ação de mascarar, turvar e justificar as relações de exploração, por meio da produção, ativação e transferência (comunicação) de 'imagens falsas', do reino da aparência, correspondentes aos desejos de eternização do mundo como tal." (SOUZA, 1984, p.94-95).

De acordo com este autor, é possível afirmar que com este tipo de veiculação, bem como com o predomínio de uma imagem falsa a respeito da sociedade capitalista, a longo prazo possa haver consequências mais graves, no que diz respeito à articulação e participação política da sociedade. Isso porque, acompanhada de uma falsa imagem, a veiculação de notícias violentas traz uma carga significativa de questionamento da autoridade do Estado e dos instrumentos legais e de defesa do cidadão, ao mesmo tempo que os espaços públicos de organização e articulação da população se restringem gradativamente. Em outras palavras, as notícias que em geral apresentam práticas violentas, em geral apontam falhas e/ou falta de alguma instituição no que diz respeito à garantia de segurança, procurando demonstrar as "ineficiências" do poder público.

O material analisado foi selecionado através de pesquisa realizada no CD-ROM FOLHA 97 - Texto integral 95/96, distribuído pelo Banco de Dados de São Paulo Ltda., onde constam integralmente os textos jornalísticos dos anos de 1995 e 1996. Equipado com um recurso para pesquisa, o CD-ROM permite que a consulta seja feita de diversas maneiras, mediante a indicação de elementos que deverão ser buscados no arquivo. Optou-se por indicar no campo "assuntos principais" e "qualquer palavra do texto" o termo violência. Assim, o resultado da pesquisa permitiu o conhecimento de uma quantidade significativa de textos a 
respeito da violência no período compreendido entre janeiro e dezembro de 1996, dos quais foram selecionados os que haviam sido publicados no caderno Cotidiano - a maciça maioria. ${ }^{2}$

A seleção da amostra foi realizada com base em alguns critérios ${ }^{3}$ através dos quais se pudesse averiguar a ocorrência - ou não - da preocupação que originou esta pesquisa - ou seja, a identificação da forma como a violência é apresentada por meio do jornal, procurando apreender como os elementos objetivos e subjetivos são articulados na construção do texto jornalístico, com o objetivo de nortear as práticas dos leitores com relação à violência.

Partindo dos elementos teóricos apresentados, a análise do material possibilitou a identificação de inúmeras questões relativas à compreensão do processo de construção da notícia, permitindo a compreensão de como os elementos objetivos e subjetivos se articulam no interior do texto jornalístico, construindo uma imagem específica a respeito da violência. Assim sendo, algumas das questões identificadas serão destacadas, sem que se esgotem as possibilidades de análise.

Foi possível observar, com base na sistemática observação dos exemplares do caderno Cotidiano do referido período, o quanto as informações são repetidas, ou seja, uma mesma informação é desmembrada em várias notícias, demonstrando que a estruturação do caderno implica a fragmentação do que está sendo veiculado. Um "clássico" exemplo disso é o conhecido "caso Bodega", ocorrido em agosto de 1996. A

- Das 1495 notícias encontradas pela pesquisa, 1057 foram publicadas no caderno Cotidiano. Das 2474 notícias cujo assunto principal era violência, publicadas nos anos de 1995 e 1996, 1495 referem-se ao ano de 1996 e 979 ao ano de 1995, demonstrando o aumento na veiculação de notícias a respeito deste assunto.

"Os critérios que orientaram a seleção podem ser assim sistematizados: a) Quanto às origens da violência, a notícia relaciona a violência com: - a crise econômica; com a política autoritária do Estado Brasileiro; - com a impunidade e/ou corrupção no Brasil. com a desqualificação do Estado; - com as características "inatas" dos supostos marginais.; b) Quanto à responsabilidade pela segurança da população, a notícia sugere que: - o Estado seja o principal responsável; - a população seja a principal responsável pela segurança; c) Quanto à sociedade civil, a notícia sugere que: - a população se isole; - a população se organize/manifeste; - a população seja cautelosa com relação aos ambientes que freqüenta; d) Quanto às alternativas para resolver a questão da violência, a notícia: - permite relacionar as diferentes alternativas com as classes sociais que as sugeriram. 
informação foi dividida em partes, cada uma delas destacando um aspecto isolado do "crime" - como agiram os assaltantes, quem eram os envolvidos, o que lhes havia acontecido no dia do crime, etc.

Um outro exemplo refere-se às notícias que foram veiculadas a respeito dos números dos assassinatos no período do carnaval. Procurando apresentar um panorama da violência no país neste período, inúmeras notícias semelhantes foram veiculadas no dia 22 de fevereiro de $1996^{+}$. Outro exemplo, ainda, diz respeito às acusações de que policiais militares fariam parte de grupo de extermínio: várias manchetes diferentes traziam o mesmo conteúdo.

Com relação à repetição, duas considerações devem ser feitas. A primeira delas refere-se ao fato de que, embora freqüente, esse expediente em geral não é inicialmente percebido pelos leitores, em virtude da distribuição das notícias no interior da página do jornal, na qual as imagens - fotos, gráficos, tabelas - são de grande importância, visto que permitem a visualização de uma página em ordem, completa.

Um segundo aspecto diz respeito às implicações dessa veiculação duplicada. Pode-se supor que este expediente seja utilizado para o preenchimento de espaços que devem ser, obrigatoriamente, ocupados diariamente com os assuntos que cabem àquele Caderno ou seção. No entanto, mais do que isso, é possível dizer que a repetição da mesma notícia reforça no leitor a mensagem - imagem - que se quer transmitir.

O processo através do qual se dá a redação dos textos jornalísticos deve ser enfatizado. É importante que se compreenda quais os interesses e objetivos que norteiam a atividade redacional. Nesse sentido, as contribuições, já apresentadas, de Ciro Marcondes Filho (1986b) são importantes. Segundo elas, o texto jornalístico deve ser feito de modo a atender os interesses do jornal, isto é, de forma padronizada. Juntamente com os processos de fragmentação e personalização das notícias, o uso da técnica e da linguagem por parte dos jornalistas atua no sentido de promover o encobrimento e/ou falseamento da reali-

\footnotetext{
${ }^{4}$ No dia 22 de fevereiro de 1996. foram veiculadas onze notícias na Folla de São Paulo a respeito dos assassinatos ocorridos no país durante o carnaval. Dessas. nove notícias estavam na mesma página.
} 
dade. Mais do que isso, a capacidade e criatividade do jornalista são, também, padronizados, na medida em que estes devem obedecer a técnicas específicas, que se restringem a responder às questões: quem, onde, como, o que, quando, por quê.

Com relação à discussão a respeito das causas da violência no Brasil, diversos textos comprovam as diferentes explicações que podem ser dadas para esta questão e que acompanham os padrões de sugestões que foram anteriormente identificados por Maria Victória Benevides (1983), correspondentes ao que ela denominou discurso oficial e discurso alternativo.

Para a Comissão de Direitos Humanos da OAB, e outras instituições similares, como o Conselho Estadual de Defesa dos Direitos da Pessoa Humana, ou mesmo o Núcleo de Estudos da Violência (NEV) da USP, os elementos geradores da violência estão diretamente relacionados às características violentas da sociedade brasileira, que limitam e dificultam o acesso dos indivíduos aos instrumentos de garantia da cidadania.

Os representantes destas instituições conseguem vislumbrar elementos subjetivos responsáveis pelo desencadeamento de processos violentos, assim como suas razões objetivas/estruturais, ligadas ao sistema político econômico brasileiro excludente. Assim, as alternativas para a resolução dessa questão, afirmam, seriam políticas, implicando uma postura mais rígida do Estado, não no sentido de praticar medidas punitivas, mas de realizar medidas preventivas, de controle e combate aos elementos geradores de violência.

"Exclusão social leva à violência, diz OAB - Presidente da Comissão de Direitos Humanos da entidade diz que criminalidade não ć ...oblema de polícia e sim de política. (...) Para o advogado Jairo funseca, presidente da Comissão de Direitos Humanos da OAB (Ordem dos Advogados do Brasil), a exclusão social alimenta a violência. Ele afirmou que," quando chega a níveis como os atuais, a criminalidade não é mais um problema de polícia e sim de política". (...) Para Fonseca, não se pode atribuir o aumento nos homicídios exclusivamente às drogas. "É inegável que há um aumento no consumo, mas não é fator determinante para o aumento dos assassinatos. (...) As pessoas vivem acumulando infelicidades e isso explode em um momento como o Carnaval ...". Maria Ignês Bierrenbach, presidente do Conselho Estadual 
de Defesa dos Direitos da Pessoa Humana, acredita que é preciso " "diminuir os níveis de violência no cotidiano das pessoas" para reduzir o número de homicídios. Ela diz que normalmente ocorre um aumento nos indicadores de violência nos finais de semana e que isso piora no Carnaval, "quando os costumes e emoções ficam mais liberados". Para Bierrenbach, é necessário resgatar a cidadania das pessoas. Ela citou o acesso à educação e a diminuição da violência policial como as medidas mais urgentes nesse sentido. "Fazer maiores investimentos em educação, no menor prazo possível, e melhorar a seleção e a formação do policial ajudariam." Na opinião de Guaracy Mingardi, 40, pesquisador do Núcleo de Estudos de Violência da USP, é difícil prevenir o homicídio comum, "como aquele que acontece em decorrência de uma briga de bar, por exemplo". "Mas o Estado pode controlar o que propicia um aumento nos homicídios, como a compra e uso de armas e os locais onde o consumo de bebidas é alto", disse. O pesquisador afirmou que dados de crimes na zona sul de São Paulo (a mais violenta da cidade) mostram que $89 \%$ dos homicídios são praticados com armas de fogo. (...)Segundo ele, poderia haver um controle dos locais de venda de bebidas alcoólicas, semelhante ao da Inglaterra, onde há restrições no horário de funcionamento. "(...) (EXCLUSÃO social... 1996; grifos da autora)

É possível citar inúmeros elementos que a mídia estimula e favorece, veiculando imagens violentas: críticas à polícia como instituição que deveria garantir a segurança da população; reconhecimento da existência de uma crise mais ampla que envolve o sistema judiciário, dificultando o encaminhamento e a resolução dos processos e favorecendo o predomínio da impunidade; violência difusa na sociedade, alimentando um círculo vicioso que favorece o sentimento de indiferença da população com relação às práticas violentas, gerando, assim, uma crise no sistema de valores da população, provocando um sentimento generalizado de desvalorização da vida, o que seria, em outras palavras, a banalização da violência, ou seja, a completa aceitação da violência como realidade cotidiana. Juntamente com outros fatores, a mídia provoca uma exacerbação desses processos, à medida que as imagens veiculadas contribuem para a consolidação desses elementos.

Os aspectos acima citados são identificados por determinados segmentos da sociedade civil: é esta a interpretação que Fermino Fechio, repre- 
sentante do Centro Santo Dias de Direitos Humanos da Arquidiocese de São Paulo, e Antonio Cláudio Mariz de Oliveira, ex-secretário da segurança pública fazem acerca da violência no Brasil. (ESTADO e sociedade...1996)

Na fala de Fermino Fechio, é possível identificar grande preocupação com a segurança e, portanto, com a polícia: embora reconheça a existência do Ministério Público e do Poder Judiciário, referindo-se a estes como "fiscalizadores" da polícia. Antonio Cláudio Mariz de Oliveira, por sua vez, tem posicionamento semelhante ao de Fechio, acrescentando a questão da responsabilidade da sociedade civil no que se refere à expansão da violência, na tentativa de socializar a responsabilidade do Estado. Segundo ele, valores egoístas e individualistas estariam "corrompendo" os indivíduos; assim, a sociedade estaria passando por uma crise de valores, uma crise ética, à medida que sentimentos como a solidariedade estariam totalmente abandonados:

“(...) Pessoas ligadas à defesa dos direitos humanos e à política de segurança pública vêem na banalização da violência e na falência das instituições as principais explicações para o crescimento dos índices de criminalidade, não só em São Paulo, mas em todo o país. Fermino Fechio, 52, presidente do Centro Santo Dias de Direitos Humanos da Arquidiocese de São Paulo, diz que o país passa por uma "uma degeneração generalizada dos órgãos que deveriam cuidar da segurança da população". Segundo ele, "a polícia está mal preparada, o Ministério Público está ausente e há Estados em que o Poder Judiciário tem 50\% das vagas de juizes não preenchidas". Essa situação, na opinião de Fechio, é agravada pelas condições econômicas do país, em especial o desemprego. Ele diz que é preciso rever várias instituições para que a criminalidade diminua. "A polícia precisa melhorar. Atualmente ela é uma instituição falida, mal equipada, o que faz com que o Estado perca a guerra contra os bandidos", avalia. Para Fechio, o Ministério Público tem que se sentir parte do processo e "fiscalizar a polícia". "A Justiça, por sua vez, precisa ser mais rápida, para evitar a sensação de impunidade, que é uma das grandes causas da violência". (...) O advogado Antônio Cláudio Mariz de Oliveira, 50, ex-secretário da Segurança Pública, vê um ' 'aviltamento da vida humana". "Há um aumento da violência não só por parte do ladrão, mas de toda a sociedade, inclusive da classe média e da elite", diz. Segundo ele, a sociedade estimula uma atitude egoísta e de indiferença às carências 
sociais. "Com isso, a sociedade perdeu suas referências éticas. Despreza os valores do ser em troca dos valores do ter. Na competição, a vida humana deixa de ter valor." A solução, na opinião do advogado, passa por um "mea culpa da elite, da classe média e da mídia". Segundo ele, a divulgação, pelos grandes meios de comunicação, da violência e de condutas e comportamentos que levam à violência, piora o problema." As camadas menos favorecidas são as mais prejudicadas. (...) Mariz de Oliveira diz que a sociedade civil deveria repensar seus valores. "Não se pode atribuir tudo ao Estado. As pessoas precisam reabraçar alguns valores perdidos, como a solidariedade."' (ESTADO e sociedade...1996; grifos da autora)

Outro elemento identificado pela análise dos textos se refere à violência policial. Muitas vezes - a maioria delas - essa violência extrapola os limites da delegacia - ou instituição fechada onde inicialmente imagina-se que ela esteja sendo praticada - e ganha as ruas, gerando grupos de extermínio e quadrilhas formadas quase sempre por policiais, o que pode ser visto com muita frequiência atualmente nas diversas emissoras de televisão. Hábeis torturadores, é possível encontrar grande quantidade de informações a respeito dos atos praticados por policiais - espancamento, extermínios, assaltos, linchamentos, roubos a bancos, entre outros.

"O deputado federal Hélio Bicudo (...), membro da Comissão de Direitos Humanos da Câmara dos Deputados, disse que o grupo "Reação", que assumiu os assassinatos de três menores em Belo Horizonte, pode ser considerado um novo Esquadrão da Morte. 'O Ministério Público deve assumir as investigações, porque se deixar nas mãos da própria polícia os culpados não serão encontrados', afirmou." (DEPUTADO crê... 1996)

"A família do ajudante de obras Jaerte Antônio, 36, acusa dois policiais militares de espancá-lo até a morte com chutes na cabeça. A Corregedoria da PM vai investigar. O espancamento teria acontecido às $19 \mathrm{~h} 30$ de sábado (...). O ajudante morreu no domingo à noite." (KRAUSZ, 1996)

"Testemunhas identificam policiais da Rota como participantes em grupos de extermínio em São Paulo. Mais dois apontam PMs 
como matadores. Duas testemunhas reconheceram ontem dois dos quatro policiais da Rota acusados de participação em chacinas em São Paulo.(...) A Folha divulgou ontem que a polícia de São Paulo havia identificado e prendido um grupo de extermúnio formado por quatro PMs da Rota. A quadrilha é acusada de participação em ao menos três chacinas e três roubos a bancos, de dezembro de 1995 a março de 1996. Nas três chacinas atribuídas à quadrilha _duas na zona leste e uma na zona sul_, 13 pessoas foram mortas. A polícia não descarta o envolvimento do grupo em outras chacinas." (LOZANO,1996b)

"O superintendente interino da Polícia Civil de Sergipe, Marcos Passos, afastou anteontem à noite do cargo cinco delegados metropolitanos acusados de envolvimento com torturas, espancamentos e corrupção. Dois deles teriam dividido uma carga de cigarros da Souza Cruz roubada na semana passada e apreendida pela polícia na terça-feira no interior do Estado." (NASCIMENTO, 1996)

Em contrapartida, a defesa da ação policial é bastante contundente. Mesmo cliante de evidências, os superiores hierárquicos dos policiais militares e civis em geral saem em sua defesa, apresentando o caso de um "suposto" excesso de violência como esporádico ou mesmo suportável, diante da realidade que "exige" este tipo de procedimento. Em oposição às manchetes que denunciam os excessos policiais, os secretários da Segurança em geral procuram criar políticas que estimulem a ação de seus subordinados, mesmo que isso implique o aumento indiscriminado do número de mortes - como é o caso da chamada operação faroeste, que gratifica a produtividade dos policiais, concedendo-lhes promoção de patente, bem como significativos aumentos salariais.

Nesse sentido, a veiculação de notícias dessa natureza tem, muitas vezes, apelado para a "necessidade de policiamento ostensivo" como forma de atacar o problema da violência. Para tanto, apontam-se dados que demonstrem a eficiência policial - diminuição no número de homicídios no Rio de Janeiro devido à repressão ao jogo do bicho.

No entanto, há de se considerar ainda o comportamento da população diante dessas notícias. É possível verificar que determinados segmentos da população são solidários às práticas policiais, demonstrando uma reação que tende a reforçar tais procedimentos, à medida que a presença da polícia na rua tem o significado de "garantir a segurança". 
"Maus policiais são minoria, diz secretário. Silva afirma que violência na PM está diminuindo. O secretário da Segurança Pública de São Paulo, José Afonso da Silva, afirma que a pesquisa Datafolha \{sobre o que gera o crime na polícia\} reflete aspectos reais. 'Acho, porém, que é uma imagem mais negativa do que a que efetivamente existe', diz. Segundo ele, 'há mais policiais que desempenham seu trabalho profissionalmente e com dignidade do que aqueles que cometem desvios de conduta e abusos'. Silva diz que a violência na polícia existe num padrão maior do que deveria. O secretário afirma que sua gestão tem tomado medidas para diminuir essa violência. O secretário apresenta o balanço de um programa que afasta policiais militares envolvidos em conflitos com morte de civis como exemplo de 'uma política de segurança voltada para a cidadania'. De setembro a dezembro, a média de civis mortos caiu de 33,5 para 15,75 pessoas por mês. 'Os desvios existem e precisam ser punidos e corrigidos', diz o comandante-geral da Polícia Militar no Estado de São Paulo, coronel Claudionor Lisboa. O comandante acredita que a violência da polícia está dentro de níveis suportáveis: 'Isso não significa que não devamos tentar diminuí-la mais'. Lisboa considera raro os casos de tortura. 'Ela é inconcebível sob todos os aspectos."' (ALENCAR; GODOY, 1996)

"Conte Lopes, 48, deputado estadual pelo PPB - 'O número mostra a omissão que existe hoje. Ela começa na secretaria e atinge os policiais, que não podem trabalhar direito porque são punidos quando, numa infelicidade, matam um bandido. A polícia está parada, por culpa de seu comando."' (FALTA projeto...1996)

"Cerqueira diz que repressão ao bicho contém homicídio no Rio (...) O secretário da Segurança Pública do Rio, Nilton Cerqueira, disse ontem que a súbita queda no número de homicídios no Estado _foram registrados quatro anteontem, contra a média de 18 diários_foi um 'efeito colateral' da repressão ao jogo do bicho, desencadeada pela Polícia Civil no mesmo dia. 'Nossa população acha que o bicho é uma coisa inocente, mas nós da polícia temos certeza de que o bicho comete outros crimes', disse o secretário. (...) Na segundafeira, dia da repressão ao bicho, também não houve assaltos a bancos (a média é de três a cinco por dia). (...)" (OPERAÇÃ̃ da policia... 1996) 
Fruto das mais diversas atuações, nas quais predomina o abuso da violência policial, e/ou o abuso do poder público, a impunidade é extremamente favorecida no contexto brasileiro, à medida que as providências necessárias de combate a este tipo de prática não são viabilizadas pelas classes dirigentes, e dificultadas ao máximo quando há mobilização da sociedade civil nesse sentido.

A respeito da mobilização da sociedade civil em torno da violência, destaca-se, a partir do ano de 1996, o considerável aumento da formação de movimentos através dos quais procura-se encaminhar reivindicações para a resolução do problema da criminalidade violenta. Iniciados por segmentos da classe média paulistana, esses movimentos proliferaram significativamente, atingindo a periferia de São Paulo, que, por sua vez, articulou-se, apresentando propostas distintas dos movimentos que se formaram na região central da cidade. Enquanto o movimento REAGE SÃO PAULO, assim como suas inúmeras ramificações (REAGERIO, REAGECAMPINAS, REAGERIBEIRÃO, REAGEINTERIOR), apresentam propostas que podem ser, de certa forma, consideradas punitivas, o movimento TOME UMA ATITUDEZONA SUL PELA NÃO-VIOLÊNCIA caracteriza-se justamente por apresentar propostas preventivas. Organizado na região mais violenta da cidade (a zona sul), o TOME UMA ATITUDE ZONA SUL PELA NÃO-VIOLÊNCIA apresenta propostas de construção de escolas e de espaços públicos, enfatizando, principalmente, a necessidade do lazer ${ }^{5}$.

"Criação de campos de futebol de várzea está entre reivindicações de novo movimento, que critica Reage SP. (...) - Zona sul pede lazer para combater crime."

Entidades de assistência social da zona sul de São Paulo lançam neste domingo o movimento Tome uma Atitude Zona Sul pela NãoViolência. O movimento pretende pedir soluções para o problema da violência nos bairros de Santo Amaro e Capela do Socorro, na zona sul. A região é a mais violenta da capital. Segundo o coordenador do movi-

\footnotetext{
S O número de movimentos pelo fim da violência aumentou significativamente desde 1996. Os mais recentes não são aqui citados em virtude da especificidade deste trabalho, que refere-se ao ano de 1996.
} 
mento, Luiz Carlos dos Santos, 40, a intenção é pedir um trabalho de prevenção e não de repressão. "Não adianta nada colocar mais polícia na rua nas áreas nobres, porque não vai acabar com a violência, só vai concentrá-la na periferia", afirma Santos. Ele critica a orientação do movimento Reage São Paulo, criado por famílias de jovens mortos em assaltos em bairros nobres. "Não nos sentimos representados pelas reivindicações do Reage São Paulo", afirma. Segundo ele, a intenção não é dividir o movimento. "Queremos trazer o problema para a nossa realidade. As reivindicações do Reage São Paulo não são as mesmas que as nossas", diz. Pauta de reivindicações:

"O movimento Tome uma Atitude Zona Sul pela Não-Violência vai apresentar no domingo uma pauta de reivindicações. Segundo Santos, os principais pontos da pauta são o investimento em lazer na periferia e o investimento em escolas. 'Não pode haver movimento contra a violência pedindo construção de cadeias. Temos que construir escolas, não cadeias.' Segundo ele, um abaixo-assinado do movimento será entregue ao governador Mário Covas e aos principais candidatos à Prefeitura de São Paulo. "Vamos pedir um investimento maior nas escolas. Além disso, consideramos importante que a prefeitura conserve os campos de várzea, que estão perdendo espaço na cidade para as escolinhas de futebol, pagas e frequientadas por garotos de classes média e alta', diz. (...)" (WASSERMANN, 1996)

É fundamental destacar, ainda, que as explicações acompanhadas de sugestões para o problema da criminalidade violenta no Brasil apresentadas pelas instituições de direitos humanos, ou ainda, pelas instituições que pesquisam o problema da violência, demonstram conhecimento da complexidade do problema, enfatizando a necessidade de medidas preventivas a curto e médio prazo.

Exemplos dessas abordagens, além da apresentada acima pelo movimento TOME UMA ATITUDEZ ZONA SUL PELA NÃO-VIOLÊNCIA, são as realizadas pelo NEV, da USP, pela OAB, pelo Conselho de Defesa da Pessoa Humana, e até mesmo pelo Ministério Público. Em contrapartida, através da análise realizada pela Secretaria de Segurança Pública, percebe-se que sua ênfase concentra-se na defesa de policiamento ostensivo para as regiões mais violentas da cidade. 


\section{Propostas para reduzir a criminalidade:}

\section{- Desarmamento}

Autoria: OAB-SP, Tribunal de Alçada Criminal de São Paulo e Ministério Público de São Paulo

Proposta: Campanha publicitária convocando a comunidade a se desarmar e alteração do Código Penal para transformar o porte ilegal de arma em crime. Hoje, é contravenção penal, punida com multa

Vantagem: Reduziria o número de pessoas armadas na cidade. Segundo a $\mathrm{OAB}$, apenas 1 em cada 16 pessoas que estão armadas quando são assaltadas não é morta ou ferida

Problemas: Alteração no Código Penal depende da adesão de mais de $50 \%$ dos deputados no Congresso Nacional; criminosos não entregariam as armas

\section{- Desarmamento}

Autoria: Núcleo de Estudos da Violência da USP

Proposta: restringir ainda mais a concessão de portes de arma, suspendendo por um ano qualquer concessão para particulares, articular com o Poder Judiciário de São Paulo e o Congresso Nacional visando criminalizar o porte e a detenção ilegais de arma, suspender a compra de armas subsidiadas por membros das PMs (...)

Vantagem: As mesmas do item anterior

Problemas: Os mesmos do item anterior

\section{- PISC (Programa Integrado de Segurança Comunitária)}

Autoria: Secretaria de Segurança Pública de São Paulo

Proposta: Aumentar o policiamento nas áreas mais violentas da cidade de São Paulo, como as zonas sul e leste

Vantagem: Número de crimes cai com maior policiamento

Problemas: Faltam policiais, a frota de carros de polícia é precária e criminalidade volta aos níveis anteriores assim que o programa é suspenso 


\section{- Aumentar o número de policiais nas ruas}

Autoria: Secretaria de Segurança Pública de São Paulo

Proposta: Colocar 8.000 homens a mais no policiamento na cidade de São Paulo

Vantagem: A mesma do item anterior

Problemas: Secretaria afirma que não consegue contratar mais homens. Cerca de $90 \%$ das pessoas que se inscrevem nos concursos são reprovados

\section{- Combate ao narcotráfico}

Autoria: Secretaria de Segurança Pública de São Paulo e Igreja Proposta: Criação da Delegacia do Crack, blitz nas ruas e atuação em conjunto com o SOS Criança para encaminhamento de menores viciados

Vantagem: Polícia acredita que boa parte dos crimes, principalmente no centro da cidade, está relacionado com o consumo e o tráfico de drogas

Problemas: Faltam denúncias por parte da população e a legislação sobre o assunto ainda é deficiente

\section{- Polícia Civil}

Autoria: Núcleo de Estudos da Violência da USP

Proposta: Reforçar os efetivos do Departamento de Homicídios e Proteção à Pessoa e do Departamento de Narcóticos, deslocar efetivo da Polícia Civil de cidades do interior com baixos índices de criminalidade para a capital, reforçar o atendimento e a averiguação das denúncias do Disque droga e tornar mais eficiente o atendimento ao público nos distritos policiais

Vantagem: Especialistas acreditam que a sensação de impunidade (crimes não resolvidos, autores não identificados) é um incentivo à violência

Problemas: Secretaria afirma que há falta de pessoal

\section{- Crime organizado}

Autoria: Núcleo de Estudos da Violência da USP

Proposta: Reprimir o jogo do bicho e apoiar projeto em trâmite no Congresso Nacional que estatiza a atividade 
Vantagem: Especialista americano afirma que combate a qualquer tipo de crime dá respeito à polícia

Problemas: Jogo do bicho ainda é considerado contravenção penal; há parlamentares contra a estatização do jogo

\section{- Proteção às vítimas e testemunhas ${ }^{6}$}

Autoria: Núcleo de Estudos da Violência da USP

Proposta: Criar um programa de informação e apoio às vítimas do crime em todos os distritos policiais e um serviço estadual de proteção às testemunhas

Vantagem: Testemunhas, muitas vezes, são a única forma que a polícia encontra para identificar criminosos. Hoje, muitas adotam a lei do silêncio por medo

Problemas: É preciso mudar a imagem que a polícia tem.

\section{- Direitos Humanos}

Autoria: Conselho de Defesa dos Direitos da Pessoa Humana Proposta: Treinar policiais (militares e civis) em direitos humanos e cidadania, dar autonomia aos institutos médicos legais e de criminalística, aumentar a visibilidade da polícia nas ruas, aprimorar o inquérito policial, equipar a Justiça e rever os prazos de conclusão de processos

Vantagem: Coibir as mortes provocadas pela polícia, acelerar os processos de investigação e julgamento

Problemas: Estado afirma ter falta de recursos

\section{- Combate ao narcotráfico}

Autoria: Governo federal

Proposta: Priorizar a segurança comunitária, criar conselhos regionais de segurança pública (...), aprimorar o profissional de segurança pública, integrar as informações criminais, adotar o registro civil único, fazer combate integrado com outros países do narcotráfico e valorizar os direitos humanos

Vantagem: Integração das informações acelera o trabalho da polícia em todo o país

Problemas: Desníveis entre as polícias dos vários Estados, falta de verbas (OAB, 1996.).

- Este projeto transformou-se na Lei n. 9807, de 13 jul. 1999 (N. da C.E.). 
Um último aspecto significativo diz respeito ao medo generalizado e difuso que prolifera entre todas as camadas da população. Acuadas pela "onda" de insegurança, as pessoas evitam a exposição pública, bem como usam de uma variedade imensa de dispositivos de segurança a serem instalados em residências e apartamentos. Ao explorar a idéia de que não haveria proteção em qualquer ambiente, a imprensa favoreceria a idéia de que o recolhimento é a melhor alternativa, e o comércio, por sua vez, e atendendo a estes apelos, já demonstra estar preparado para este tipo de situação, articulando-se em torno do atendimento domiciliar.

Embora nem sempre percebida, a consequiência imediata deste tipo de mentalidade pode ser verificada no predomínio dos sentimentos de individualidade e pavor que atinge toda a sociedade:

"As pessoas estão entrando na síndrome do medo, gente comum e sem antecedentes está andando armada e se tornando eventuais assassinos", afirma o delegado Antero Leonardo Bianchi, 54, titular do $100^{\circ}$ Distrito Policial, no extremo sul da cidade."

No outro extremo dos índices da violência, a síndrome do medo é a mesma.(...)

"Para Paulo Sérgio Pinheiro, do Núcleo de Estudos da Violência da USP, a sociedade está vivendo uma "síndrome equivocada". "Não é verdade que está havendo uma caça aos estudantes brancos. A classe média está se contaminando pelo clima artificial e amplificado numa conjuntura político eleitoral". Pinheiro diz que a cidade precisa de um movimento Reage São Paulo, mas em outro lugar. "As mortes estão aumentando entre os jovens da periferia pobre. É lá que se deve protestar, não apenas na avenida Paulista." (BIANCARELLI, 1996)

A consequiência imediata desses processos aponta para a necessidade de uma mudança urgente de mentalidade, à medida que a sociedade, acuada, estaria indo em direção oposta ao que objetiva: buscando formas de resolver os problemas - isolando-se, garantindo sua própria segurança - estaria gradativamente minando as possibilidades 
de superação dessa realidade, ao afastar-se dos espaços públicos de articulação e defesa de seus interesses e necessidades. Iludidos pelas imagens da violência, os indivíduos estariam fortalecendo os elementos responsáveis pela sua geração.

"São Paulo é hoje uma cidade de muros. Amedrontados pelo aumento do crime violento e descrentes da eficácia da polícia ou da Justiça, os moradores procuram se proteger o mais que podem. Erguem muros, reforçam as grades e fechaduras, compram armas, consomem as mais diversas tecnologias de segurança e contratam guardas privados. Também saem menos, mudam-se para condomínios fechados, trocam as compras e o lazer que lhes façam usar as ruas pelos shoppings e, se podem, abandonam os transportes coletivos para se mover apenas com seus carros. Para completar, tendem a apoiar medidas violentas para lidar com a criminalidade, como a pena de morte _muitas vezes confundida com execução sumária pela polícia_e a atacar os que defendem os direitos humanos. (...) Para fazer face à violência, os moradores de São Paulo se aprisionam, adotam soluções privadas de proteção e progressivamente abandonam a esfera pública. (...) Tudo indica que esse tipo de reação alimenta o ciclo da violência, em vez de contrapor-se a ele. O que poderia ser efetivo para interromper esse ciclo é a retomada e o fortalecimento da esfera pública, algo que os cidadãos de São Paulo parecem resistir a entender. Frente ao medo e ao aumento da criminalidade violenta, é inevitável que as pessoas tentem se proteger. O problema é que as soluções privadas e violentas em geral não apenas não são as mais eficazes, como também podem ter resultados contrários aos esperados.(...) Violência não é remédio para a violência. (...) Se o uso da força e das armas fizesse baixar a criminalidade violenta, São Paulo seria a cidade mais segura do mundo, já que em nenhum outro lugar a polícia mata mais do que aí (compara-se as quase 1.500 mortes pela polícia em $1992 \mathrm{com}$ as 25 pela polícia de Los Angeles!).

Obviamente, não se faz face ao crime sem polícia. Mas a polícia que controla a violência é aquela que impõe a ordem, ao mesmo tempo em que respeita a lei e os cidadãos. É uma polícia bem treinada, bem paga, não-corrupta e não-violenta, que trabalha pela comunidade em vez de lhe causar medo. É o tipo de polícia que na Europa se fortaleceu junto com uma Justiça eficaz e igualitária, que dá aos cidadãos a noção de que não haverá impuni- 
dade.(...) Mas é ilusão pensar que se pode construir uma sociedade segura apenas dentro dos muros de espaços protegidos. $\mathrm{O}$ que se consegue com esses muros é aprisionar as pessoas e segregar os mais pobres, mas não necessariamente maior segurança.(...) Não é o abandono da esfera pública, mas a sua apropriação pelos cidadãos de todas as classes sociais, que permite criar uma melhor qualidade de vida e controlar a violência. (...) Quando os cidadãos de todos os grupos sociais perceberem que têm que sair de trás dos muros, se apropriar do espaço público e como co-cidadãos organizar a segurança de todos, quem sabe o problema da violência comece a encontrar o seu encaminhamento." (CALDEIRA, 1996, p.5-6)

Esta afirmação de Teresa Caldeira é suficientemente clara para demonstrar o quanto a sociedade civil tem se orientado erroneamente, na tentativa de se prevenir de uma violência que atinge todos os espaços, ao mesmo tempo que sugere alternativas de abertura que vão contra todos os discursos atualmente propagados a esse respeito. Para ela, a saída está justamente na prática que vem sendo sistematicamente minada, isto é, na atuação coletiva da população, a fim de se apropriar dos espaços que lhe cabem, através dos quais, articulando-se conjuntamente, possam construir a cidadania, de modo que esta se prolongue por todas as camadas da sociedade, permitindo a atuação livre de cidadãos conscientes.

Nesse sentido, cabe perguntar qual tem sido o papel da imprensa nesse contexto, e qual deveria verdadeiramente ser. Em que medida ela tem permitido a conscientização da população em torno da alternativa de alargamento dos espaços públicos proposta por Caldeira? Em que medida suas veiculações têm, ao contrário, favorecido a idéia de isolamento e/ou de autodefesa da população como alternativa para a "onda" tão amplamente divulgada de violência? Quais os interesses reais que orientam a atuação da imprensa junto à população: a venda de seu produto ou a possibilidade de discussão, por parte da sociedade, de questões de interesse (e necessidade) geral, de modo a possibilitar a construção de soluções alternativas para os problemas atualmente vivenciados?

Sem que essas questões sejam seriamente analisadas e discutidas, a participação da imprensa no atual debate a respeito da vio- 
lência implicará a existência de lacunas que, por sua vez, possibilitarão o questionamento da maciça divulgação que se faz em torno deste assunto.

\section{Considerações finais}

A violência no Brasil possui inúmeras facetas e é possível afirmar que nenhum trabalho poderá apresentar resultados finais acerca desta problemática. Por acompanhar a dinâmica da sociedade brasileira, ela deve ser continuamente problematizada, à medida que novos elementos se colocam constantemente para a discussão.

Nesse sentido, este trabalho procurou apenas apontar para a necessidade da realização de uma abordagem ainda mais completa, na qual seja possível estudar aspectos que não puderam ser investigados neste momento.

Uma questão relevante seria em relação aos próprios leitores/ consumidores das notícias. Como estes têm se posicionado diante do que é diariamente veiculado pela imprensa? Até que ponto eles podem ser tomados como elementos "passivos" numa estrutura social marcadamente autoritária? É possível pensar que exista uma estrutura internalizada nos indivíduos, que norteia seus interesses e suas ações, permitindo que as veiculações do jornal e dos meios de comunicação como um todo encontrem terreno fértil e se reproduzam?

Em outras palavras, se a realidade brasileira, muito embora alguns caminhos alternativos sejam apontados, tende a produzir na grande maioria da população um sentimento vingativo, através de quais mecanismos isso se torna possível? Uma análise mais detalhada dos textos jornalísticos permitiria, ainda, uma investigação acerca da presença das classes sociais no jornal. Nesse sentido, poderia ser questionado: em que medida o espaço concedido para as diferentes manifestações violentas refletem a estrutura social maior, que estratifica e exclui os indivíduos?

Estas são apenas algumas das questões que poderão vir a ser problematizadas em outros trabalhos que poderão trazer novas contribuições. 


\section{Referências Bibliográficas}

ADORNO, Theodor W. A indústria cultural. In: COHN, Gabriel. (Org.). Comminicaf̧ão e indístria cultural. São Paulo: Ática, 1986, Coleção Grandes Cientistas Sociais.

ALENCAR, Kennedy; GODOY, Marcelo. Maus policiais são a minoria. diz o secretario. Folha de São Paulo, São Paulo 14/01/96.

BENEVIDES, Maria Victória. Violência, povo e polícia: Violência urbana no noticiário de imprensa. São Paulo: Brasiliense, 1983

BIANCARELLI, Aureliano. Especialistas apontam "síndroma do pânico". Folha de São Paulo, São Paulo, 17 agu. 1996.

CALDEIRA. Teresa. A cidade fortificada. Folha de São Paulo. São Paulo. 22 set. 1996. Caderno mais!, p. 5.6

CAMPOS, Edmundo. Sobre sociólogos, pobreza e crime. Dados, Rio de Janeiro. v. 23, n.3, p. 377-383, 1980.

CHAUÍ, Marilena de Souza. A não violência do brasileiro: um mito interessantíssimo. Revista Almanaque, São Paulo, n.11, p.16-24, 1980.

COSTA, Jurandir Freire da. A devoração da esperança no próximo. Follha de São Paulo, São Paulo, 22 set. 1996. Caderno mais!, p.5.8

DEPUTADO crê em novo esquadrão da morte. Folha de São Paulo. São Paulo. 16 mar. 1996.

DICAS de segurança em SP. Folha de São Paulo, São Paulo 1 dez. 1996.

ESTADO e sociedade civil são criticados. Folha de São Paulo, São Paulo. 25 fev. 1996.

EXCLUSÃO social leva a violência, diz OAB. Folha de São Paulo. São Paulo. 22 fev. 1996.

FALTA projeto de governo contra a violência. Folha de São Paulo. São Paulo 9 mar. 1996.

GRAMSCI, Antônio. Jornalismo. In: GRAMSCI. Antônio. Os intelectuais e a organização da Cultura. 3.ed. Rio de Janeiro: Civilização Brasileira. 1979.

HABERMAS, Jürgen. Do jornalismo literário aos meios de comunicação de massa. In: MARCONDES FILHO, Ciro (Org.) Imprensa e Capitalismo. São Paulo: Kairós, 1984. 
KRAUSZ, Renato. Família acusa PM de matar ajudante. Folha de São Paulo, São Paulo. I5 maio 1996.

LOZANO, André. Mais de dois apontam PMS como matadores. Folha de São Paulo, São Paulo, 29 maio 1996 b.

Paulo, 23 fev. 1996a.

Medo cria 'toque de recolher' em SP. Folha de São Paulo, São

MARCONDES FILHO, Ciro. Diluindo os mitos da violência política. In Violência política. São Paulo: Moderna, 1987.

Ideologias são as práticas cotidianas. In: MARCONDES FI-

LHO. Ciro. Quem manipula quem? Poder e massa na indústria da Cultura e da Comunicação no Brasil. Petrópolis: Vozes, 1986a.

(Org.). Imprensa e Capitalismo. São Paulo: Kairós, 1984.

MARCONDES

Imprensa e estruturação econômica da sociedade. In:

FILHO, Ciro. O capital da notícia. São Paulo: Ática, 1986 b.

MARTINS, José de Souza. As condições do estudo sociológico dos linchamentos no Brasil. Estudos Avançados, São Paulo, v.9, n.25, p.295-310, 1995.

NASCIMENTO. Eugênio. Cinco delegados são afastados em Aracaju, acusados de tortura. Folha de São Paulo, São Paulo 28 set. 1996.

OAB. Propostas para reduzir a criminalidade. Folha de São Paulo, São Paulo, 20 ago. 1996

OPERAÇÃO da policia do Rio combate jogo do bicho. Folha de São Paulo, São Paulo.18 jun. 1996.

PINHEIRO, Paulo S. O passado não está morto: nem passado é ainda. In: DIMENSTEIN, G. Democracia em pedaços. São Paulo: Companhia das Letras, 1996a.

As relações criminosas. Folha de São Paulo, São Paulo, 22 set. 1996b. Caderno mais!, p. 5.7.

SOUZA. Ailton Benedito. Violência no Rio de Janeiro: outro nome para a luta de classes. Rèvista Comunicação e Política, Rio de Janeiro, v.2. n.12, mar./jun.1984.

SUSSEKIND, Elizabeth. A manipulação política da criminalidade. Ciência Hoje. Violência: Encarte Especial, v.5, n 28, jan./fev. 1987. 
TOLEDO, José Roberto. A epidemia da violência. Folha de São Paulo. São Paulo. 22 set. 1996.

TORRES. Sergio. Rio gratifica policial que mata mais. Folha de São Paulo. São Paulo, 19 jul. 1996.

TREVISAN. Claudia . Periferia tem extermínio masculino. Folha de Siono Palo. São Paulo I abr. 1996.

VELHO, Gilberto. As vítimas preferenciais. Ciência Hoje. Violência: Encarte Especial, v.5, n.28, jan./fev. 1987.

WASSERMANN, Rogério. Zona Sul pede Lazer para combater o crime. Follut de São Paulo. São Paulo, 18 set. 1996.

\section{Abstract}

The urban violence has been a question quite discussed by the means of communications and can be notice from the quantity of news that appear about the most different acts considered as "violent". That's why this article tries to make a reflexion about the urban violence and the way it has been treated by the written midia having as starting point the analysis of the news about violent practices occured on the urban environment and published by the newspaper Folha de São Paulo the year of 1996.

Key-words: urban violence: press: news. 